\title{
Neuroprotection against stroke and encephalopathy after cardiac surgery
}

\author{
DANIEL G. JOVIN, KARL G. KATLAPS, BEN K. ELLIS, BENITA DHARMARAJ*
}

\begin{abstract}
Cardiothoracic Research, Department of Surgery, Hunter Holmes McGuire Veterans Affairs Medical Center, Richmond, VA, USA *Corresponding author: Benita Dharmaraj, MD, MHSA; Cardiothoracic Research, Department of Surgery, Hunter Holmes McGuire Veterans Affairs Medical Center, 1201 Broad Rock Boulevard, Surgical Service (112), Richmond, VA 23249, USA; Fax: +1 80467554 00; E-mail: benita.dharmaraj@va.gov
\end{abstract}

(Received: March 29, 2018; Revised manuscript received: June 28, 2018; Accepted: December 10, 2018)

\begin{abstract}
Cerebral ischemia in the perioperative period is a major risk factor for stroke, encephalopathy, and cognitive decline after cardiothoracic surgery. After coronary artery bypass grafting, both stroke and encephalopathy can result in poor patient outcomes and increased mortality. Neuroprotection aims to lessen the severity and occurrence of further injury mediated by stroke and encephalopathy and to aid the recovery of conditions already present. Several pharmacological and non-pharmacological methods of neuroprotection have been investigated in experimental studies and in animal models, and, although some have shown effectiveness in protection of the central nervous system, for most, clinical research is lacking or did not show the expected results. This review summarizes the value and need for neuroprotection in the context of cardiothoracic surgery and examines the use and effectiveness of several agents and methods with an emphasis on clinical trials and clinically relevant neuroprotectants.
\end{abstract}

Keywords: neuroprotection, cardiothoracic surgery, cardiac surgery, stroke, encephalopathy, pharmacological agents, anesthesia, sedation

\section{Stroke and Encephalopathy After Cardiac Surgery}

The number of major heart operations and procedures is constantly growing, as advancements in surgical procedures, medical technology, and clinical understanding allow for a greater number of "high-risk" patients to undergo invasive treatment. An increasing number of patients undergoing major operations and subjected to possible postoperative complications compounds surgical risk factors. Thus, the need for an effective neuroprotective is on the rise to protect a growing patient population by preventing dangerous perioperative and postoperative complications and degeneration. Neuroprotection comprises the strategies employed to safeguard the central nervous system (CNS) from injury or degeneration, specifically through the maintenance of oxygen and nutrient supply to preserve metabolic function. Neuroprotective efforts have employed a variety of agents to protect the CNS and mitigate risks specifically relating to cardiothoracic surgery. One of the main procedures in cardiothoracic surgery is coronary artery bypass grafting
(CABG), and every year about 300,000 surgeries are performed in the USA [1]. Patients who had undergone CABG have been found to have a $1.5 \%-5.2 \%$ risk of perioperative stroke along with a subsequent increase in mortality [2]. A prospective 25-year study determined that about $1.5 \%-2.0 \%$ of patients undergoing CABG experienced a stroke, and $\mathrm{CABG}$ patients who experienced strokes had worse survival. After l year, survival for CABG patients who experienced stroke was $70 \%$ compared to $95.3 \%$ for patients who did not experience stroke. The survival rate after 10 years was $37 \%$ for patients with intra- and postoperative stroke versus $68 \%$ for non-stroke CABG patients [3].

Generally, carotid stenosis is a major risk factor for stroke in CABG patients along with diabetes on insulin and peripheral arteriopathy [4]. Unstable angina, low left ventricle ejection fractions, postoperative atrial fibrillation, and postoperative hypotension are additional risk factors of stroke in CABG patients with a previous history of stroke. While about $5 \%$ of CABGs may result in ischemic stroke, $7.4 \%$ result in ischemic stroke when the patients have a history of stroke even if pharmacological

This is an open-access article distributed under the terms of the Creative Commons Attribution-NonCommercial 4.0 International License, which permits unrestricted use, distribution, and reproduction in any medium for non-commercial purposes, provided the original author and source are credited, a link to the CC License is provided, and changes - if any - are indicated. 
neuroprotectants like propofol are used [5]. Cerebral ischemia causes large release of glutamate, which results in stimulation of the N-methyl-D-aspartate (NMDA) receptor and subsequent calcium-dependent death-signaling leading to neuronal death. Excitotoxicity, neurotoxicity mediated by glutamate, is an exaggeration of neuronal excitation and has been classified as a primary contributor to ischemic neuronal death. Excitotoxicity is facilitated by sodium ions although removal of sodium ions effectively limits only neuronal swelling not neuronal death. Neuron survival is promoted mainly via stimulation of voltage-gated calcium channels. Blocking the NMDA receptor is associated with many side effects arising from the variety and importance of neurological functions involving these receptors; therefore, for maximum safety and efficacy, NMDA receptors must be targeted/blocked with therapies immediately before or after the onset of stroke [6].

A prospective single-center study recorded the incidence of stroke to be $2.4 \%$ within 14 days following $\mathrm{CABG}$, and almost half of patients who experienced stroke experienced it within $24 \mathrm{~h}$ of CABG [7]. For this reason, stroke remains a prominent threat to a patient's survival although its incidence in cardiac surgery may be increasing due to more "high-risk" patients being admitted into hospitals and undergoing cardiothoracic surgery over the past 20 years. Since patients are vulnerable in the perioperative and early postoperative period, identifying surgical neuroprotection methods is paramount. These methods must be evaluated on long-term outcomes they provide for patients along with how successfully they protect patients in the period during and shortly after surgery.

Besides stroke, another important risk associated with cardiothoracic surgery is encephalopathy. Encephalopathy is described as including "confusion, delirium, seizures, coma, and prolonged alteration in mental status, combativeness, and agitation," but definitions and diagnosis methods vary across the literature. This state may be underreported due to inconsistencies in measuring and evaluating its presence but has been observed to occur in $8.4 \%-32 \%$ of patients after CABG $[8,9]$. Microemboli, hypoperfusion, and atrial fibrillation are all risk factors for encephalopathy in the postoperative period of cardiac surgery [10]. The importance of these conditions is that they prolong hospital stay and may cause long-term morbidity and disability. The average length of hospital stay for CABG without complications is less than a week (6.6 days), whereas with encephalopathy, this stay is extended on average to approximately 2 weeks [11]. Stroke increases the length of stay to 17.5 days on average with a mortality of $22.0 \%$. In addition, patients with encephalopathy experience a prolonged stay (15.2 days on average) and a $7.5 \%$ mortality rate, five times the average mortality after CABG for those without encephalopathy or stroke [11].

A quarter of patients undergoing CABG may also show signs of one form of encephalopathy, cognitive decline, within 3 months of surgery. Postoperative cognitive dysfunction (POCD) remains an elusive phenomenon to measure, diagnose, prevent, and predict as it can affect a variety of independent cognitive domains, which may not all be evident through the arbitrary testing methods used. Over half of the patients typically experience cognitive decline a week after cardiac surgery, but this number falls to $30 \%-50 \%$ at $8-10$ weeks and $10 \%-20 \%$ at 1 year. Risk factors for postoperative cognitive decline are similar as those for encephalopathy: microemboli, hypoperfusion, arrhythmias, and exaggerated inflammatory responses [12]. A single-center study has demonstrated postoperative delirium in patients who underwent elective cardiac operations to be a predictor of postoperative frailty and major adverse cardiac events. Age and surgery duration are also established risk factors for postoperative delirium, which has previously been shown as a strong predictor of 10-year mortality and cognitive decline. In addition, postoperative frailty has been repeatedly shown as a marker for adverse cardiovascular outcomes, so its prevention through neuroprotective methods to limit POCD and delirium is relevant for evaluating the potential use of a neuroprotective agent [13].

Studies have begun to look into the option of preventing these postoperative problems, which are believed to be caused by cerebral ischemia in the perioperative period. Both stroke and encephalopathy are considered to be caused by microemboli, hypoperfusion during surgery, and postoperative atrial fibrillation. To prevent CNS morbidity, these neurological events must be either reduced in severity, or prevented entirely although stroke and encephalopathy become greater risks in the presence of cerebrovascular disease, comorbid conditions, and other factors. Many different methods have been tried to prevent the occurrence of stroke and encephalopathy in cardiac surgery including the use of pharmacological agents and other non-pharmacological methods. A summary of pharmacological agents and their clinical study for usage in cardiac surgery and application in non-cardiac surgery is shown in Table $I$.

\section{Pharmacological Neuroprotection in Cardiac Surgery}

Various pharmacological agents have been found to alter blood flow to the nervous system. Cardiac surgery patients are prime candidates for pharmacological neuroprotectants as they frequently suffer from cerebral ischemia, while research has shown that anesthesia increases the ischemia tolerance of the brain.

Barbiturates are promising neuroprotectants as they reduce the amount of energy needed by neurons in the brain. Thiopental, a barbiturate, demonstrated a significantly decreased incidence of neuropsychiatric dysfunction following cardiopulmonary bypass, but reflection 
Table I Prospective clinical summary table for pharmacological agents

\begin{tabular}{|c|c|c|c|c|}
\hline Study & Intervention & Surgery & Patients enrolled & $\begin{array}{l}\text { Postoperative } \\
\text { follow-up }\end{array}$ \\
\hline Nussmeier et al. [14] & Thiopental (barbiturate) & Cardiac/open-ventricle & $182(93$ control $)$ & 1 day, 10 days \\
\hline Zaidan et al. [16] & Thiopental (barbiturate) & CABG & 300 (151 control $)$ & 2 days, 5 days \\
\hline Kruger et al. [18] & $\begin{array}{l}\text { Steroids, barbiturates, } \\
\text { mannitol, and } \\
\text { combination }\end{array}$ & Aortic dissection type A & $2,137$ (1,026 control $)$ & 30 days \\
\hline Royse et al. [25] & $\begin{array}{l}\text { Propofol and desflurane } \\
\text { (volatile anesthetic) }\end{array}$ & CABG & 177 (90 desflurane) & 3 months \\
\hline Roach et al. [26] & Propofol & Aortic or mitral valve & $\begin{array}{l}225 \text { (116 control/ } \\
\text { sufentanil) }\end{array}$ & $\begin{array}{l}1 \text { day, } 6 \text { days, } \\
60 \text { days }\end{array}$ \\
\hline Mathew et al. [28] & Lidocaine & Cardiac & 241 (127 control $)$ & 6 weeks, 1 year \\
\hline Mitchell et al. [30] & Lidocaine & Cardiac & 158 (77 control $)$ & 10 weeks, 25 weeks \\
\hline Wang et al. [31] & Lidocaine & CABG & $118(61$ control $)$ & 9 days \\
\hline Arrowsmith et al. [32] & Remacemide & CABG & $171(84$ control $)$ & 8 weeks \\
\hline Bhudia et al. [35] & Magnesium sulfate & CABG and/or valve & 350 (176 control $)$ & $\begin{array}{l}1 \text { day, } 4 \text { days, } \\
3 \text { months }\end{array}$ \\
\hline Mathew et al. [36] & Magnesium & Cardiac & 389 (191 control) & 6 weeks \\
\hline Mack et al. [37] & Magnesium & Carotid endarterectomy & 92 (43 control) & 1 day \\
\hline Hudetz et al. [40] & Ketamine & Cardiac surgery & $52(26$ control $)$ & l week \\
\hline Avidan et al. [4l] & Ketamine & $\begin{array}{l}\text { Major cardiac and } \\
\text { non-cardiac }\end{array}$ & $672(222$ control $)$ & $\begin{array}{l}\text { Twice a day in first } \\
3 \text { days }\end{array}$ \\
\hline Lockwood et al. [43] & Xenon & CABG & 16 & $\begin{array}{l}\text { Immediately } \\
\text { postoperatively }\end{array}$ \\
\hline Al Tmimi et al. [46] & $\begin{array}{l}\text { Xenon and sevoflurane } \\
\text { (volatile anesthetic) }\end{array}$ & CABG & $42(21$ xenon $)$ & 6 months \\
\hline Rasmussen et al. [47] & Xenon and propofol & Knee replacement & 39 (21 xenon) & $\begin{array}{l}\text { Between } 3 \text { and } \\
5 \text { days and } 3 \text { months }\end{array}$ \\
\hline Coburn et al. [48] & Xenon and desflurane & Elective surgery & 38 (18 xenon $)$ & $6-12 \mathrm{~h}$ and $66-72 \mathrm{~h}$ \\
\hline Forsman et al. [49] & Nimodipine & Cardiac & 35 (17 control $)$ & 6 months \\
\hline Legault et al. [50] & Nimodipine & Valve replacement & 150 (75 nimodipine) & $\begin{array}{l}1 \text { week, } 1 \text { month, } \\
6 \text { months }\end{array}$ \\
\hline Mardani et al. [56] & Dexamethasone (steroid) & CABG & $\begin{array}{l}93(43 \\
\text { dexamethasone) }\end{array}$ & 1 day, 2 days, 3 days \\
\hline Levy et al. [57] & Aprotinin & CABG & 287 (91 control) & Up to 12 days \\
\hline Mangano et al. [60] & Aprotinin & CABG & $\begin{array}{l}4,374(1,072 \\
\text { aprotinin })\end{array}$ & $\begin{array}{l}6 \text { weeks, } 6 \text { months, } \\
\text { and annually for } \\
5 \text { years }\end{array}$ \\
\hline Drenger et al. [67] & ACE inhibitors & CABG & $4,224(2,043$ control $)$ & 30 days \\
\hline Billings et al. [74] & Atorvastatin & Cardiac & 199 (97 control) & 2 days \\
\hline Zheng et al. [75] & Rosuvastatin & Cardiac & $1,922(962$ control $)$ & 5 days \\
\hline Grieco et al. [84] & Ganglioside GMI & Cardiac & 19 (11 control) & $\begin{array}{l}1 \text { day, I week, } \\
6 \text { months }\end{array}$ \\
\hline
\end{tabular}

CABG: coronary artery bypass grafting

determined that the neuroprotective effects of thiopental were mainly due to its ability to reduce the embolic load to the brain $[14,15]$. Following CABG, patients who were given thiopental provided in the same way as in the study of Zaidan et al. had an incidence of stroke, which was higher but not significantly different from the placebo group [16]. Although barbiturates decrease neuronal metabolic need, they are not a perfect neuroprotective 
agent due to their prolonged effect and reduction of cerebral blood flow [17]. In addition, in type A aortic dissection surgery, barbiturates demonstrated no prevention of postoperative mortality-corrected permanent neurological dysfunction or reduction of 30-day mortality [18]. A lack of clinical evidence and complications from extended effect keep barbiturates from being effective neuroprotectants.

Volatile anesthetics provide a solution to the problem experienced with barbiturates as they act quickly and then dissipate, although properties vary among agents. The variability in expected outcomes of volatile anesthetics use is a result of confusion surrounding their anesthetic mechanisms [19]. Volatile anesthetics can ideally provide neuroprotective effects through increased intracellular calcium, increased cerebral blood flow, downregulation of metabolism, excitotoxicity inhibition, reduction of oxidative stress, and increased potassium channel activity, although there is uncertainty about which agents are optimal and how dose dependent their effects are [19-21]. Overall, meta-analyses comparing isoflurane versus sevoflurane determined volatile anesthetic choice that does not affect postoperative outcomes for cardiac surgery patients [22]. Mini-mental state examination scores in a meta-analysis of patients undergoing cardiac surgery with cardiopulmonary bypass were significantly higher $24 \mathrm{~h}$ postoperatively for patients who received inhalation of anesthesia agents, such as volatile anesthetics than for patients receiving intravenous anesthesia agents, including propofol, thiopental, and ketamine. Data for parameters at longer time points were not collected, and intravenous and inhalation anesthesia showed no significant differences in the parameters regarding cerebral metabolism and oxygenation [23]. One of the first studies to examine surgical levels of anesthesia in humans for an inhalational agent, sevoflurane, demonstrated significant global reduction of cerebral absolute blood flow, which may indicate that other volatile anesthetics would cause similar outcomes [24]. Volatile anesthetics have failed to be neuroprotective clinically but may potentially be used in anesthesia and paired with neuroprotective agents for optimal outcomes.

Sedation with propofol, a sodium channel blocker, was tested as an alternative for general anesthesia. Propofol treatment showed no difference in incidence of POCD at 3 months compared to patients treated with a volatile anesthetic, desoflurane, although the propofol group had a significantly higher incidence than desoflurane before hospital discharge [25]. Propofol increased incidence of adverse neurologic outcomes in valve surgery patients at postoperative days 1 and 2 and 5-7 days after surgery, although no significant differences were found 50-70 days postoperatively [26]. Propofol was found to be an unreliable neuroprotective method as it globally reduces absolute cerebral blood flow [24]. During cardiopulmonary bypass, propofol decreased cerebral blood flow velocity and cerebral oxygen extraction [27]. Propofol's lack of clinical success and reduction of cerebral blood flow make it a poor neuroprotective candidate.

Lidocaine is a sodium channel blocker and local anesthetic, which was also tested as a neuroprotective agent in cardiac surgery and was successful in non-diabetic patients, but diabetic patients were still susceptible to POCD despite lidocaine treatment [28]. Lidocaine also has a fast onset and lasts for an intermediate amount of time. It presumably reduces cerebral inflammation by crossing the blood-brain barrier [29]. While postoperative lidocaine treatment for $48 \mathrm{~h}$ following cardiac surgery decreased POCD, 12-h lidocaine infusion in CABG patients showed no difference in cognitive and memory testing [30]. However, a different study found that POCD 9 days after surgery was reduced in CABG patients receiving perioperative lidocaine [31]. Lidocaine is a very promising neuroprotective agent, but to establish it as a neuroprotective agent, more studies are needed that track stroke and ischemic events in addition to POCD at longer postoperative intervals.

Another sodium channel blocker and non-competitive NMDA antagonist, remacemide, was found to improve cognitive health according to measured change in learning ability, but remacemide was not associated with reduced POCD, and the study failed to include patients with a history of neurological or psychiatric disorders [32]. Because the NMDA receptor-mediated pathways modulate excitotoxicity, NMDA receptor antagonists are promising neuroprotective agents to minimize neuronal death [33].

Magnesium is also an attractive neuroprotective candidate because of its blocking of both the NMDA receptor and voltage-gated calcium channel [34]. Magnesium has shown effectiveness improving short-term postoperative memory and cortical control over brain stem function after CABG [35]. A prospective, randomized, double-blind, placebo-controlled clinical trial determined that perioperative magnesium during cardiac surgery did not reduce POCD. Subgroup analyses found that low-dose magnesium improved neurocognitive function on postoperative day 1, while placebo-treated patients were not different from those treated with high-dose magnesium, but magnesium treatment did not result in any significant, long-term neurocognitive improvements [36]. Patients undergoing carotid endarterectomy in a double-blind, placebo-controlled trial who received low-dose magnesium demonstrated less cognitive decline than patients treated with placebo or high-dose magnesium [37]. Low-dose magnesium, like lidocaine, is a promising neuroprotectant but clinical evidence of its effect in preventing stroke and ischemic events in addition to POCD is needed.

Ketamine, which is also an NMDA receptor antagonist, was investigated for neuroprotective properties due to its potent inhibition of neurotransmission and anti-inflammatory features [38]. Ketamine increased 
absolute regional cerebral blood flow in a concentrationdependent manner in all brain regions studied, and when provided as an anesthetic in cardiac surgery, it has also limited the incidence of POCD and postoperative delirium [39, 40]. However, in a multicenter, international randomized trial, preoperative, subanesthetic, low-dose ketamine was not associated with a difference in postoperative delirium incidence but did increase hallucination and nightmare occurrence [41].

Xenon, another NMDA receptor antagonist, has been tested as a neuroprotective agent as well, despite concerns about its potential to exacerbate injury during cardiac surgery by increasing the volume of bubbles in air-based emboli due to its propensity to create expanding gaseous bubbles [42]. However, a study showed patients using xenon and undergoing CABG while on cardiopulmonary bypass had no major organ damage and no cerebral embolization [43]. Xenon can reduce neurodegeneration and protect cortical neurons through NMDA receptor antagonism as well as prevention of cell death through oxidative stress mechanisms [44]. A study by Laitio et al. [45] is one of the few studies to experiment with xenon monoanesthesia in humans and found that xenon anesthesia decreased regional cerebral blood flow. In addition, postoperative delirium was shown to occur more frequently in off-pump CABG patients treated with xenon anesthesia compared to patients treated with sevoflurane anesthesia in a small, randomized pilot trial [46]. While xenon has demonstrated some neuroprotective effects in non-cardiac surgery, it has displayed limited potential as a neuroprotectant in cardiac surgery $[47,48]$.

Nimodipine, a calcium channel blocker, has been found to improve patient's verbal fluency and visual retention without any resulting signs of ischemic damage in patients undergoing cardiac surgery [49]. An early terminated, double-blind, randomized clinical trial using nimodipine for patients receiving cardiac valve surgery was terminated early because of an unprecedented increase of death and bleeding events in the nimodipine groups [50]. Overall, nimodipine has been mainly limited to studies within cellular neurological models and protected against glucose deprivation, trophic withdrawal, and surgical stresses where it has demonstrated efficacy [51, 52]. More neuroprotection studies are needed to reestablish nimodipine's candidacy as a neuroprotective agent.

Corticosteroids have also been studied as agents for neuroprotection because they reduce body's inflammatory response, which could reduce the incidence of POCD and benefit in ischemic stroke and encephalopathy [53]. In spite of that, corticosteroids may also cause atrophy, neurotoxicity, neuroendangerment, and hyperglycemia after administration [54]. More recent research drew promising conclusions about corticosteroids' neuroprotective properties. Neonatal piglets treated with methylprednisolone demonstrated significantly increased mean global cerebral blood flow recovery when treated prior to cardiopulmonary bypass and deep hypothermic circulatory arrest (DHCA). Regional recovery of cerebral blood flow in the cerebellum, brain stem, and basal ganglia was all significantly higher for the piglets treated with corticosteroids when compared to the piglets in the control group. Cerebral oxygen metabolism recovery was also significantly higher for the corticosteroid-treated piglets [55]. In aortic dissection type A surgery, steroid treatment resulted in a significantly lower postoperative mortality-corrected permanent neurological dysfunction rate but no change in 30-day mortality [18]. Dexamethasone, another corticosteroid, was given before anesthesia and taken for 3 days postoperatively by patients undergoing CABG, which resulted in significantly better mini-mental state examination results on the first two postoperative days and reduced incidence of postoperative delirium on the first postoperative day. Moreover, intubation time and hospital length of stay for patients treated with dexamethasone were significantly shorter than the patients in the control group. Incidence of transient ischemic attack and stroke was lower for the corticosteroid-treated group, yet still comparable [56]. Larger clinical studies are warranted to validate the neuroprotective effects of corticosteroids.

Aprotinin is a trypsin inhibitor, which has been tested as a neuroprotective agent and shown in multiple studies to reduce the incidence of stroke following cardiac surgery $[57,58]$. Aprotinin is able to cross the bloodbrain barrier. Nevertheless, research has found aprotinin to have no direct effect on POCD and even increased risk of long-term mortality, renal failure, and stroke rate for patients post-CABG $[59,60]$. The benefits shown by aprotinin are obtained due to an indirect effect that the drug had on limiting overall blood loss and reducing the occurrence of cerebral emboli, but the increased mortality risk led to its removal from clinical use [61].

Beta-blockers are an existing therapy used to reduce blood pressure, which have properties that may make them effective neuroprotectants. They have established efficacy for hemodynamic stabilization and are encouraged for use in both high-risk patients undergoing vascular surgery and intermediate risk patients undergoing non-cardiac surgery as they can prevent cardiac events [62]. Beta-blockers administered before stroke onset have demonstrated no association with mortality, whereas beta-blockers administered in the acute stage of stroke had a reduced mortality. The impaired autonomic functions caused by beta-blockers reduce stroke incidence and improve outcomes by reducing inflammation and blood pressure derangements along with other pathophysiological mechanisms [63]. A retrospective study found that preoperative beta-blocker use has demonstrated no association with postoperative delirium, stroke, or mortality following cardiac surgery. Patients who received betablockers had decreased odds of longer delirium duration 
and increased odds of acute kidney injury stage 2, but these conclusions were refuted following secondary analysis [64]. On the contrary, it was also shown that perioperative beta-blocker treatment during CABG reduces incidence and risk of adverse neurologic events, stroke, and coma following surgery [65]. The neuroprotective benefits of beta-blockers in cardiac surgery are not definitive, but further study is warranted to understand if betablocker treatment should be continued perioperatively and can be paired with an anesthetic agent.

Similar to aspirin, angiotensin converting enzyme (ACE) inhibitors can act on thrombus formation through fibrinolysis, plaque stabilization, and collateral circulation enhancement in the same way aspirin was shown to improve stoke outcomes [66]. They are another medication used to reduce blood pressure whose use as a neuroprotectant is being explored. An international, multicenter study found that ACE inhibitor treatment for on-pump CABG surgery continued postoperatively resulted in reduced incidence of cardiac and renal events, but rates of cerebral event and inhospital mortality were comparable. However, withdrawing ACE inhibitor therapy acutely can increase total complication incidence, chronic heart failure, renal event, and myocardial infarction [67]. ACE inhibitors may not have expressly shown neuroprotective properties in the study mentioned, but their neuroprotective and cardioprotective properties have been shown repeatedly. Based on National Institute of Health Stroke Scale scores, patients treated with ACE inhibitors before their stroke, who were typically older and had a greater history of cardiac disease, diabetes, and hypertension, had significantly reduced stroke severity and ischemic tissue volumes, which were smaller but not statistically significant. There was also no difference in baseline blood pressure for both patient groups during admission, which indicates that neuroprotective mechanisms of ACE inhibitors are independent of their effects on blood pressure. Cardioembolic strokes made up a greater subset of strokes and lacunar strokes made up a smaller subset of strokes in ACE inhibitor patients compared to non-ACE patients, although the differences were not significant [68]. High-risk patients, those with either vascular disease or diabetes along with another cardiovascular risk factor, received ramipril, an ACE inhibitor that had reduced rates of death due to cardiovascular causes, death due to any cause, and stroke [69]. ACE inhibitors are seemingly capable neuroprotectants that warrant further study in the setting of cardiac surgery on the effects that pretreatment and postoperative treatments have on POCD, stroke, ischemic events, and mortality.

Statins, a lipid-lowering medication and type of 3-hydroxy-3-methyl-glutaryl-coenzyme A (HMG-CoA) reductase inhibitors, are a potential neuroprotectant because they can exert pleiotropic properties with anti-atherosclerotic, anti-thrombotic, anti-oxidative, and anti-inflammatory effects [33]. Statins have demonstrated a general ability to upregulate neural growth factors and reduce neuroinflammation in cases of Alzheimer's (AD) and Parkinson's disease. In addition, they have demonstrated a clinical link to reducing corresponding incidence and severity of inflammation for CNS pathologies. Through antioxidant effects like downregulation of both nitric oxide and reactive oxygen species, statins reduce incidence of both ischemic and hemorrhagic stroke [70]. Statins have not demonstrated consistent neuroprotective effects during cardiac surgery. A retrospective study of patients undergoing valve surgery who received statins pre- and postoperatively demonstrated reduced odds ratios for stroke and renal dysfunction versus the control group, but a more recent retrospective meta-analysis of randomized controlled trials concluded that perioperative statin use is associated with acute kidney injury and no differences in stroke or mortality postoperatively $[71,72]$. It may be that reported statin-based neuroprotection outcomes are determined by the dosages as well because concentrations between $100 \mathrm{nM}$ and $\mathrm{l} \mu \mathrm{M}$ lead to effective neuroprotection while greater concentrations typically reduce cell viability [73]. Regardless of neuroprotective effects, perioperative statins have shown repeated increase of acute kidney injury incidence in randomized, clinical trials, and researchers are favoring to discontinue the use of statin treatment in cardiac surgery [74-76]. On the whole, statins are unqualified neuroprotectants as they present limited promise in prevention of neurological complications and put patients at risk of acute kidney injury when used in cardiac surgery.

\section{Lipids as Neuroprotective Agents in Cardiac Surgery}

Certain lipids have shown promise in the search for an effective neuroprotective agent, and research on their role in neuronal function has made them interesting candidates. For example, a study discovered that patients with Huntington's disease (HD) as well as animal and cell models of HD had reduced a synthesis of monosialoganglioside (GM1), and lower GMI levels increase HD cell susceptibility to stress and apoptotic stimuli [77]. Other neurodegenerative diseases, such as $\mathrm{AD}$, are affected by gangliosides as a non-toxic amyloid beta-protein has been shown to bind with ganglioside GMl in AD brains [78]. Yet, research is ongoing to better understand the relationship of gangliosides and neuronal actors. Lipids, especially gangliosides, have shown some promise as neuroprotectants in the experimental setting but lack convincing clinical results.

One of the major concerns regarding lipid use during cardiac surgery is the potential for strokes postoperatively. 
Besides preventing further injury, neuroprotective agents need to contribute to the recovery of existing injury. In vitro studies using GMl suggested that GMI has protective effects in the acute injury phase and decreases excitatory amino acid-related neurotoxicity [79]. GMl also prevented further losses of fatty acids and crucial in aiding the restoration of these levels over time. A study by Mahadik et al. [80] using GMl on rats concluded that it restores membrane fatty acid levels in ischemic tissue after cortical focal ischemia. Lipids demonstrated more promise in a dog model where pretreatment and perioperative infusion of GMl during cardiopulmonary bypass and $2 \mathrm{~h}$ of hypothermic circulatory arrest (HCA) preserved glutamate receptor expression in the dogs [81]. In addition, GMl demonstrated the ability to reduce nitric oxide production and HCA-induced apoptosis in dogs treated with GMl preoperatively and postoperatively during $2 \mathrm{~h}$ of HCA [82].

GMl ganglioside therapy was first used in a clinical setting for acute ischemic stroke by Argentino et al. The study showed that patients with ischemic stroke who had been given GMl treatment (either with or without hemodilution as further neuroprotection) had significantly greater neurologic improvement on the Canadian Neurological scale score during the first 10 days of treatment compared to patients who had been given either placebo or placebo with hemodilution [83]. Although GMl-treated patients had a higher degree of neurological improvement in all comparisons, no significant differences were detected between groups after 21 and 120 days after their stroke, and no significant difference in mortality was detected between groups. The causes of death were evenly distributed among patients who did and did not receive GMl treatment [83]. Further research has determined that during cardiac surgery the effect of gangliosides may be negligible. A qualitative review of randomized clinical trials concluded that the incidence of POCD did not differ between GMI patients and the control group. Intravenous GMI prior to cardiac surgery under cardiopulmonary bypass resulted in no significantly different clinical change scores for neurological cerebral, neurological non-cerebral, and neuropsychological performance changes [84].

In most studies of gangliosides, GMl was used as a neuroprotective agent, but there are other ways to suggest that gangliosides as neuroprotectants. For example, a study by Kharlamov et al. [85] of LIGA20, a lyso derivative of GMl, concluded that oral administration reduces infarct size and the associated cognitive deficit after cortical thrombosis in rats. Lipids might be best used as a neuroprotective treatment method to prevent and reduce neurological injuries rather than as a perioperative therapy. For cardiac surgery, lipids use could be explored in conjunction with another neuroprotective agent, which can limit stroke and mortality outcomes and allow patients to benefit from the preservation and improvement of neurological biology provided by lipids.

\section{Non-Pharmacological and Procedural Neuroprotection in Cardiac Surgery}

Non-pharmacological methods and procedural methods are also being investigated for potential neuroprotection. Depth of anesthesia is a potential mechanism mediating surgical vulnerability and postoperative recovery. In non-cardiac surgery, deeper anesthesia, treatment which resulted in a lower bispectral index regimen, resulted in significantly improved processing speed and comparable working memory and verbal memory 4-6 weeks postoperatively in comparison to patients with a higher bispectral index regimen [86]. However, a separate meta-analysis of postoperative delirium found perioperative light anesthesia to be associated with decreased incidence of delirium in non-cardiac surgery. Concerns of publication bias were mentioned, and the power analyses determine that the sample size was inadequate for definite conclusion to be drawn [87]. Although what level of anesthesia is optimal for patients during surgery remains uncertain, basic monitoring of anesthesia depth provides an effective neuroprotective method. A study found that general anesthesia surgical patients who had their bispectral index data monitored were less likely to present with postoperative delirium. Deep anesthesia, a value $<20$ on the bispectral index scale, was independently predictive for increased postoperative delirium. POCD was not associated with bispectral index monitoring, although its incidence was reduced [88].

The most predominant practice is the use of DHCA, which decreases the cerebral metabolic $\mathrm{O}_{2}$ demand by about $6 \%$ for each $1{ }^{\circ} \mathrm{C}$ change [89]. Hypothermia also attenuates the body's neuro-inflammatory response. Circulatory arrest is usually carried out at a temperature between 18 and $20^{\circ} \mathrm{C}$, and at $18{ }^{\circ} \mathrm{C}$, the metabolic rate is between $12 \%$ and $25 \%$ of the normal rate $[90,91]$. During DHCA, there is increased production of neuronal NO, which inhibits NO synthase and subsequently reduces neuronal injury, but canine models have shown that glutamate is also released during DHCA that can contribute to secondary neuronal injury and neuronal death [92]. Despite increased glutamate production, hypothermia has been shown to improve neurological outcomes and survival post cardiac arrest, thereby proving to be an effective neuroprotectant against ischemic brain injury through attenuation of excitotoxicity and other mechanisms $[93,94]$. The safe duration for DHCA is still under study and complications can arise from both an extended period of DHCA and the rewarming process. HCA with on-pump CABG was identified as a risk factor 


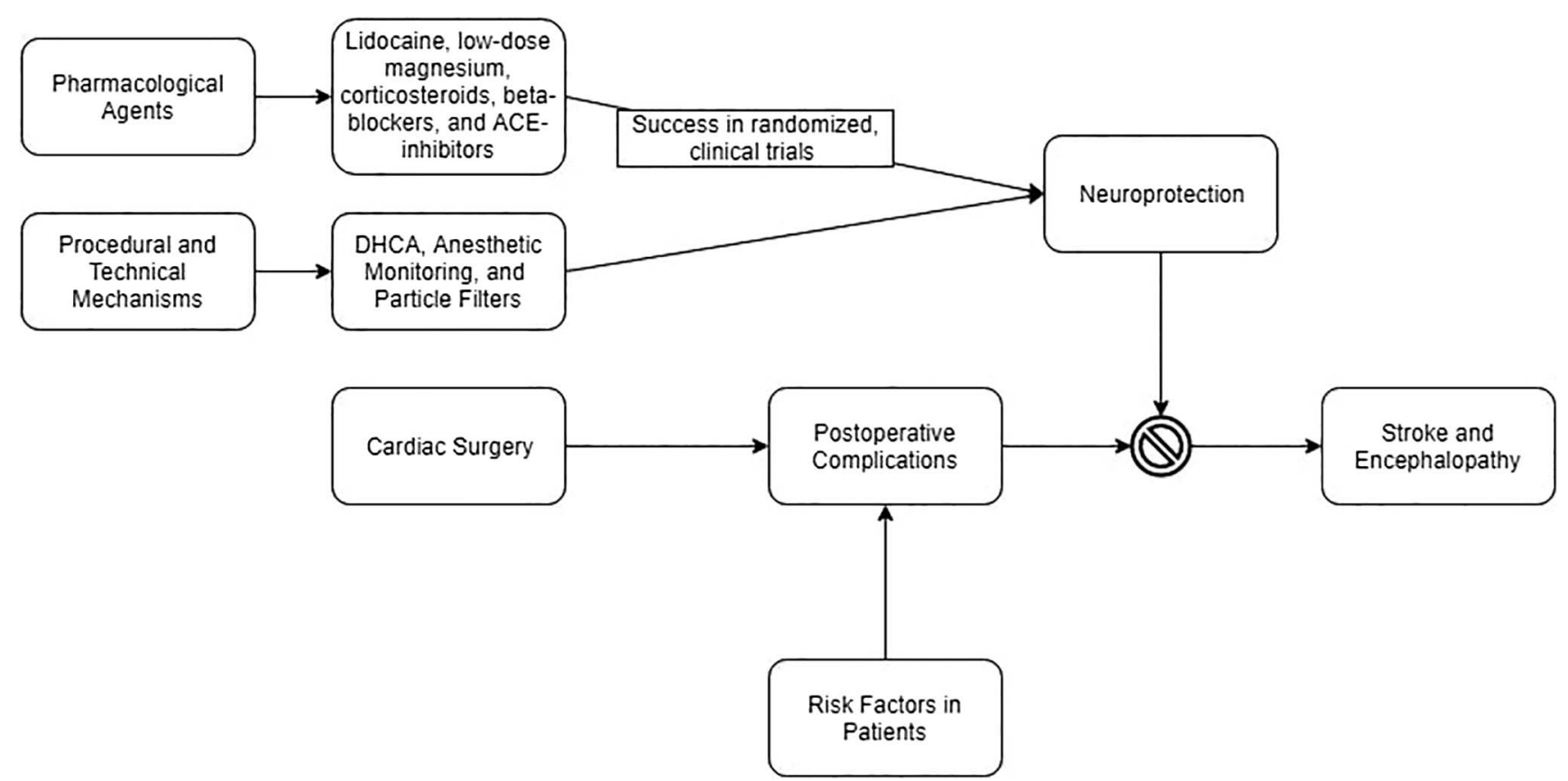

Fig. 1. Schematic overview of neuroprotectants and neuroprotection in the context of cardiac surgery. DHCA: deep hypothermic circulatory arrest; ACE inhibitors: angiotensin converting enzyme inhibitors

for both intraoperative and postoperative stroke, which mainly causes concerns about rewarming issues [95]. The majority of patients can handle half an hour of circulatory arrest at $18{ }^{\circ} \mathrm{C}$ without significant impairment with neurological complications for 30, 45, and 60 min of DHCA being $4 \%, 7.5 \%$, and $10.7 \%$, respectively $[90,91]$. Surgery duration is also a known risk factor for neurological outcomes in cardiac surgery, which may compound DHCA complications. Rewarming, if performed incorrectly, can occasionally result in hyperthermia, which aggravates ischemic brain insults in animals and worsens neurocognitive outcomes after bypass in humans [96-98].

Another non-pharmacological method of neuroprotection is the use of particle filters. These particle filters aim to eliminate, or at least reduce, air microbubbles identified as a contributing factor for neuropsychological disorders after $\mathrm{CABG}$ and risk factors for stroke and encephalopathy. Research has shown particle filters to be an effective method to reduce gaseous microemboli in CABG [99, 100]. High-risk patients receiving intraaortic filtration during combined intracardiac and CABG procedures in an international multicenter, randomized trial demonstrated a significantly decreased time in the intensive care unit, non-fatal stroke, and mortality. Intraaortic filters had a particulate embolus capture rate of $97 \%$, and they could potential reduce the effect of gaseous emboli by separating large bubbles into smaller, less dangerous bubbles [101]. Moreover, particle filters have also shown to improve neuropsychological performance assessed through the Center for Epidemiologic Studies Depression Scale and the Speilberg State and Trait Anxiety Inventory tests post-CABG [100].

\section{Conclusions}

The risks involved with cardiac surgery could be reduced with the use of an effective neuroprotective agent to help avert stroke and encephalopathy, and the search for neuroprotectants is still ongoing. There are methods and agents that have been shown to be effective, but further research is needed for most of them to become clinically established methods of neuroprotection. Many of the pharmacological agents presented here have shown conflicting results and would need further research in a clinical setting, although ethical concerns may not allow treating humans with unproven agents. Lidocaine, lowdose magnesium, corticosteroids, beta-blockers, and ACE inhibitors have proven neuroprotective capabilities and deserved further study. Although ganglioside and lipids in general lack major clinical evidence as neuroprotective agents, there may be a potential for them to be used along with anesthetics or to be modified into other, more effective, pharmaceutical agents. In regard to nonpharmacological methods, DHCA is a valuable method for neuroprotection, but care must be taken in limiting its duration and effectively rewarming, while particle filters and anesthetic monitoring should both be employed in cardiac surgery. An overview of currently validated and promising options can be seen in Fig. 1 .

Funding sources: No financial support was received for this study.

Authors' contribution: All authors conceived the study and its design and coordination. DGJ wrote the first draft, and then all authors made 
significant contributions and approved the final version of the manuscript.

Conflict of interest: The authors report no financial or other relationship relevant to the subject of this article.

Acknowledgements: The authors would like to thank Dr. Tudor Jovin, Dr. Cris Constantinescu, and Dr. Alexandra Zirra for a critical review of earlier of versions of the manuscript.

\section{References}

1. Diodato M, Chedrawy EG: Coronary artery bypass graft surgery: The past, present, and future of myocardial revascularisation. Surg Res Pract 2014, 1-6 (2014)

2. van Dijk D, Moons KG, Nathoe HM, van Aarnhem EH, Borst C, Keizer AM, Kalkman CJ, Hijman R: Association between early and three month cognitive outcome after off-pump and on-pump coronary bypass surgery. Heart 90, 431-434 (2004)

3. Tarakji KG, Sabik JF, Bhudia SK, Batizy LH, Blackstone EH: Temporal onset, risk factors, and outcomes associated with stroke after coronary artery bypass grafting. JAMA 305, 381-390 (2011)

4. da Costa MAC, Gauer MF, Gomes RZ, Schafranksi MD: Risk factors for perioperative ischemic stroke in cardiac surgery. Rev Bras Cir Cardiovasc 30, 365-372 (2015)

5. Cao L, Li Q, Bi Q, Yu QJ: Risk factors for recurrent stroke after coronary artery bypass grafting. J Cardiothorac Surg 6, 157 (2011)

6. Lai TW, Zhang S, Wang YT: Excitotoxicity and stroke: Identifying novel targets for neuroprotection. Prog Neurobiol 115, 157-188 (2014)

7. Lee EJ, Choi KH, Ryu JS, Jeon SB, Lee SW, Park SW, Park SJ, Lee JW, Choo SJ, Chung CH, Jung SH, Kang DW, Kim JS, Kwon SU: Stroke risk after coronary artery bypass graft surgery and extent of cerebral artery atherosclerosis. J Am Coll Cardiol 57, 1811-1818 (2011)

8. Bucerius J, Gummert JF, Borger MA, Walther T, Doll N, Falk V, Schmitt DV, Mohr FW: Predictors of delirium after cardiac surgery delirium: Effect of beating-heart (off-pump) surgery. J Thorac Cardiovasc Surg 127, 57-64 (2004)

9. Rolfson DB, McElhaney JE, Rockwood K, Finnegan BA Entwistle LM, Wong JF, Suarez-Almazor ME: Incidence and risk factors for delirium and other adverse outcomes in older adults after coronary artery bypass graft surgery. Can J Cardiol 15, 771-776 (1999)

10. McKhann GM, Grega MA, Borowicz LM, Baumgartner WA, Selnes OA: Stroke and encephalopathy after cardiac surgery: An update. Stroke 37, 562-571 (2006)

11. McKhann GM, Grega MA, Borowicz LM Jr, Bechamps M, Selnes OA, Baumgartner WA, Royall RM: Encephalopathy and stroke after coronary artery bypass grafting: Incidence, consequences, and prediction. Arch Neurol 59, 1422-1428 (2002)

12. Patel N, Minhas JS, Chung EML: Risk factors associated with cognitive decline after cardiac surgery: A systematic review. Cardiovasc Psychiatry Neurol 2015, 1-12 (2015)

13. Ogawa M, Izawa KP, Satomi-Kobayashi S, Tsuboi Y, Komaki K, Gotake Y, Sakai Y, Tanaka H, Okita Y: Impact of delirium on postoperative frailty and long term cardiovascular events after cardiac surgery. PLoS One 12, e0190359 (2017)

14. Nussmeier NA, Arlund C, Slogoff S: Neuropsychiatric complications after cardiopulmonary bypass: Cerebral protection by a barbiturate. Anesthesiology 64, 165-170 (1986)

15. Todd MM, Hindman BJ, Warner DS: Barbiturate protection and cardiac surgery: A different result. Anesthesiology 74, 402-405 (1991)
16. Zaidan JR, Klochany A, Martin WM, Ziegler JS, Harless DM, Andrews RB: Effect of thiopental on neurologic outcome following coronary artery bypass grafting. Anesthesiology 74, 406-411 (1991)

17. Donegan JH, Traystman RJ, Koehler RC, Jones MD Jr , Rogers $\mathrm{MC}$ : Cerebrovascular hypoxic and autoregulatory responses during reduced brain metabolism. Am J Physiol 249, H421-H429 (1985)

18. Kruger T, Hoffmann I, Blettner M, Borger MA, Schlensak C, Weigang E: Intraoperative neuroprotective drugs without beneficial effects? Results of the German Registry for Acute Aortic Dissection Type A (GERAADA). Eur J Cardiothorac Surg 44, 939-946 (2013)

19. Zuo Z: Are volatile anesthetics neuroprotective or neurotoxic? Med Gas Res 2, 1-9 (2012)

20. Liu H, Tariq R, Liu G, Yu L: Pharmacological cerebral protection in cardiac surgery: An update. J Anesth Perioper Med 1, 23-37 (2007)

21. Matchett GA, Allard MW, Martin RD, Zhang JH: Neuroprotective effect of volatile anesthetic agents: Molecular mechanisms. Neurol Res 31, 128-134 (2009)

22. Zorrilla-Vaca A, Nunez-Patino RA, Torres V, Salazar-Gomez Y: The impact of volatile anesthetic choice on postoperative outcomes of cardiac surgery: A meta-analysis. BioMed Res Int 2017, 1-12 (2017)

23. Chen F, Duan G, Qu Z, Zou Z, Li H: Comparison of the cerebroprotective effect of inhalation anaesthesia and total intravenous anaesthesia in patients undergoing cardiac surgery with cardiopulmonary bypass: A systematic review and meta-analysis. BMJ Open 7, 1-11 (2017)

24. Kaisti KK, Metsahonkala L, Teras M, Oikonen V, Aalto S, Jaaskelainen S, Hinkka S, Scheinin H: Effects of surgical levels of propofol and sevoflurane anesthesia on cerebral blood flow in healthy subjects studied with positron emission tomography. Anesthioslogy 96, 1358-1370 (2002)

25. Royse CF, Andrews DT, Newman SN, Stygall J, Williams Z, Pang J, Royse AG: The influence of propofol or desflurane on postoperative cognitive dysfunction in patients undergoing coronary artery bypass surgery. Anaesthesia 66, 455-464 (2011)

26. Roach GW, Newman MF, Murkin JM, Martzke J, Ruskin A: Ineffectiveness of burst suppression therapy in mitigating perioperative cerebrovascular dysfunction. Anesthesiology 90, 12551264 (1990)

27. Ederberg S, Westerlind A, Houltz E, Svensson SE, Elam M, Ricksten SE: The effects of propofol on cerebral blood flow velocity and cerebral oxygen extraction during cardiopulmonary bypass. Anesth Analg 86, 1201-1206 (1998)

28. Mathew JP, Mackensen GB, Phillips-Bute B, Grocott HP, Glower DD, Laskowitz DT, Blumenthal JA, Newman MF: Randomized, double-blinded, placebo controlled study of neuroprotection with lidocaine in cardiac surgery. Stroke 40, 880-887 (2009)

29. Tan AMY, Amoako D: Postoperative cognitive dysfunction after cardiac surgery. Contin Educ Anaesth Crit Care Pain 13, 218-223 (2013)

30. Mitchell SJ, Merry AF, Frampton C, Davies E, Grieve D, Mills BP, Webster CS, Milsom FP, Willcox TW, Gorman DF: Cerebral protection by lidocaine during cardiac operations: A follow-up study. Ann Thorac Surg 87, 820-825 (2009)

31. Wang D, Wu X, Li J, Xiao F, Liu X, Meng M: The effect of lidocaine on early postoperative cognitive dysfunction after coronary artery bypass surgery. Anesth Analg 95, 1134-1141 (2002)

32. Arrowsmith JE, Harrison MJ, Newman SP, Stygall J, Timberlake N, Pugsley WB: Neuroprotection of the brain during cardiopulmonary bypass: A randomized trial of remacemide during coronary artery bypass in 171 patients. Stroke 29, 2357-2362 (1998)

33. Lou M, Selim M (2011): The future of brain protection in cardiac surgery. In: Brain Protection in Cardiac Surgery, eds Bonser RS, Pagano D, Haverich A, Springer, London, pp. 229-237 
34. van den Bergh WM, Dijkhuizen RM, Rinkel GJ: Potentials of magnesium treatment in subarachnoid haemorrhage. Magnes Res 17, 301-313 (2004)

35. Bhudia SK, Cosgrove DM, Naugle RI, Rajeswaran J, Lam BK, Walton E, Petrich J, Palumbo RC, Gillinov AM, AppersonHansen C, Blackstone EH: Magnesium as a neuroprotectant in cardiac surgery: A randomized clinical trial. J Thorac Cardiovasc Surg 131, 853-861 (2006)

36. Mathew JP, White WD, Schinderle DB, Podgoreanu MV, Berger M, Milano CA, Laskowitz DT, Stafford-Smith M, Blumenthal JA, Newman MF: Intraoperative magnesium administration does not improve neurocognitive function after cardiac surgery. Stroke 44 3407-3413 (2013)

37. Mack WJ, Kellner CP, Sahlein DH, Ducruet AF, Kim GH, Mocco J, Zurica J, Komotar RJ, Haque R, Sciacca R, Quest DO, Solomon RA, Connolly ES, Heyer EJ: Intraoperative magnesium infusion during carotid endarterectomy: A double-blind placebo-controlled trial. J Neurosurg 110, 961-967 (2009)

38. Bhutta AT, Schmitz ML, Swearingen C, James LP, Wardbehnoche WL, Lindquist DM, Glasier C, Tuzcu V, Prodhan P, Dyamenahalli U, Imamura M, Jaquiss RD, Anand KJ: Ketamine as a neuroprotective and anti-inflammatory agent in children undergoing surgery on cardiopulmonary bypass. Pediatr Crit Care Med 13, 328-337 (2012)

39. Langsjo JW, Kaisti KK, Aalto S, Hinkka S, Aantaa R, Oikonen V, Sipila H, Kurki T, Silvanto M, Scheinin H: Effects of subanesthetic doses of ketamine on regional cerebral blood flow, oxygen consumption, and blood volume in humans. Anesthesiology 9, 614-623 (2003)

40. Hudetz JA, Iqbal Z, Danhi SD, Patterson KM, Byrne AJ, Hudetz AG, Pagel PS, Warltier DC: Ketamine attenuates post-operative cognitive dysfunction after cardiac surgery. Acta Anaesthesiol Scand 53, 864-872 (2009)

41. Avidan MS, Maybrier HR, Abdallah AB, Jacobsohn E, Vlisides PE, Pryor KO, Veselis RA, Grocott HP, Emmert DA, Rogers EM, Downey RJ, Yulico H, Noh GJ, Lee YH, Waszynski CM, Aya VK, Pagel PS, Hudetz JA, Muench MR, Fritz BA, Waberski W, Inouye SK, Mashour GA: Intraoperative ketamine for prevention of postoperative delirium or pain after major surgery in older adults: An international, multicentre, double-blind, randomised clinical trial. Lancet 390, 267-275 (2017)

42. Jungwirth B, Gordan ML, Blobner M, Schmehl W, Kochs EF, Mackensen GB: Xenon impairs neurocognitive and histologic outcome after cardiopulmonary bypass combined with cerebral air embolism in rats. Anesthesiology 104, 770-776 (2006)

43. Lockwood GG, Franks NP, Downie NA, Taylor KM, Maze M: Feasibility and safety of delivering xenon to patients undergoing coronary artery bypass graft surgery while on cardiopulmonary bypass: Phase I study. Anesthesiology 104, 458-465 (2006)

44. Lavaur J, Lemaire M, Pype J, Le Nogue D, Hirsch EC, Michel PP: Xenon-mediated neuroprotection in response to sustained, lowlevel excitotoxic stress. Cell Death Discov 2, 1-9 (2016)

45. Laitio RM, Kaike KK, Laangsjo JW, Aalto S, Salmi E, Maksimow A, Aantaa R, Oikonen V, Sipila H, Parkkola R, Scheinin H: Effects of xenon anesthesia on cerebral blood flow in humans: A positron emission tomography study. Anesthesiology 106, 1128-1133 (2007)

46. Al Tmimi L, Van Hemelrijck J, Van de Velde M, Sergeant P, Meyns B, Missant C, Jochmans I, Posen K, Coburn M, Rex S: Xenon anaesthesia for patients undergoing off-pump coronary artery bypass graft surgery: A prospective randomized controlled pilot trial. Br J Anaesth 115, 550-559 (2015)

47. Rasmussen LS, Schemhl W, Jakobsson J: Comparison of xenon with propofol for a supplementary general anaesthesia for knee replacement: A randomized study. Br J Anaesth 97, 154-159 (2006)
48. Coburn M, Baumert JH, Roertgen D, Thiel V, Fries M, Hein M, Kunitz O, Fimm B, Rossaint R: Emergence and early cognitive function in the elderly after xenon or desflurane anaesthesia: A double-blinded randomized controlled trial. Br J Anaesth 98, 756-762 (2007)

49. Forsman M, Olsnes BT, Semb G, Steen PA: Effects of nimodipine on cerebral blood flow and neuropsychological outcome after cardiac surgery. Br J Anaesth 65, 514-520 (1990)

50. Legault C, Furberg CD, Wagenknecht LE, Rogers AT, Stump DA, Coker L, Troost BT, Hammon JW: Nimodipine neuroprotection in cardiac valve replacement. Stroke 27, 593-598 (1996)

51. Lecht S, Rotfeld E, Arien-Zakay H, Tabakman R, Matzer H, Yaka R, Lelkes PI, Lazarovici P: Neuroprotective effects of nimodipine and nifedipine in the NGF-differentiated PCl2 cells exposed to oxygen-glucose deprivation or trophic withdrawal. Int J Dev Neurosci 30, 465-469 (2012)

52. Herzfeld E, Strauss C, Simmermacher S, Bork K, Hortskorte R, Dehghani F, Scheller C: Investigation of the neuroprotective impact of nimodipine on Neuro2a cells by means of a surgerylike stress model. Int J Mol Sci 15, 18453-18465 (2014)

53. Lanier WL: The prevention and treatment of cerebral ischemia. Can J Anaesth 46, R46-R56 (1999)

54. Sapolsky RM: Stress, glucocorticoids, and damage to the nervous system: The current state of confusion. Stress 1, 1-19 (1996)

55. Langley SM, Chai PJ, Jaggers JJ, Ungerleider RM: Preoperative high dose methylprednisolone attenuates the cerebral response to deep hypothermic circulatory arrest. Eur J Cardiothorac Surg 17, 279-286 (2000)

56. Mardani D, Bigdelian H: Prophylaxis of dexamethasone protects patients from further post-operative delirium after cardiac surgery: A randomized trial. J Res Med Sci 18, 137-143 (2013)

57. Levy JH, Pifarre R, Schaff HV, Horrow JC, Albus R, Spiess B, Rosengart TK, Murray J, Clark RE, Smith P: A multicenter, double-blind, placebo-controlled trial of aprotinin for reducing blood loss and the requirement for donor-blood transfusion in patients undergoing repeat coronary artery bypass grafting. Circulation 92, 2236-2244 (1995)

58. Frumento RJ, O'Malley CM, Bennett-Guerrero E: Stroke after cardiac surgery: A retrospective analysis of the effect of aprotinin dosing regimens. Ann Thorac Surg 75, 479-483 (2003)

59. Mangano DT, Tudor IC, Dietzel C: The risk associated with aprotinin in cardiac surgery. N Engl J Med 354, 353-365 (2006)

60. Mangano DT, Miao Y, Vuylsteke A, Tudor IC, Juneja R, Filipescu D, Hoeft A, Fontes ML, Hillel Z, Ott E, Titov T, Dietzel C, Levin J: Mortality associated with aprotinin during 5 years following coronary artery bypass graft surgery. JAMA 297, 471-479 (2007)

61. Murkin JM: Lessons learned in antifibrinolytic therapy: The BART trial. Semin Cardiothorac Vasc Anesth 13, 127-131 (2009)

62. Kadoi Y, Saito S: Possible indications of beta-blockers in the perioperative period other than prevention of cardiac ischemia. J Anesth 24, 81-95 (2010)

63. Sykora M, Siarnik P, Diedler J: $\beta$-blockers, pneumonia, and outcome after ischemic stroke. Stroke 46, 1269-1274 (2015)

64. O’Neal JB, Billings FT, Liu X, Shotwell MS, Liang Y, Shah AS, Ehrenfeld JM, Wanderer JP, Shaw AD: Effect of preoperative beta-blocker use on outcomes following cardiac surgery. Am J Cardiol 120, 1293-1297 (2017)

65. Amory DW, Grigore A, Amory JK, Gerhardt MA, White WD, Smith PK, Schwinn DA, Reves JG, Newman MF: Neuroprotection is associated with beta-adrenergic receptor antagonists during cardiac surgery: Evidence from 2,575 patients. J Cardiothorac Anesth 16, 270-277 (2002)

66. Padma MV: Angiotensin-converting enzyme inhibitors will help in improving stroke outcome if given immediately after stroke. Ann Indian Acad Neurol 13, 156-159 (2010) 
67. Drenger B, Fontes ML, Miao Y, Mathew JP, Gozal Y, Aronson S, Dietzel C, Mangano DT: Patterns of use of perioperative ACE inhibitors in CABG surgery with cardiopulmonary bypass: Effects on in-hospital morbidity and mortality. Circulation 126, 261-269 (2012)

68. Selim M, Savitz S, Linfante I, Caplan L, Schlaug G: Effect of prestroke use of ACE inhibitors on ischemic stroke severity. BMC Neurol 5, 10 (2005)

69. The Heart Outcome Prevention Evaluation Study Investigators, Yusuf S, Dagenais G, Pogue J, Bosch J, Sleight P: Effects of an angiotensin-converting enzyme inhibitor, ramipril, on cardiovascular events in high-risk patients. N Engl J Med 342, 145-153 (2000)

70. McFarland AJ, Anoopkumar-Dukie S, Arora DS, Grant GD, McDermott CM, Perkins AV, Davey AK: Molecular mechanisms underlying the effects of statins in the central nervous system. Int J Mol Sci 15, 20607-20637 (2014)

71. Fedoruk LM, Wang H, Conaway MR, Kron IL, Johnston KC: Statin therapy improves outcomes after valvular heart surgery. Ann Thorac Surg 8, 1521-1526 (2008)

72. Putzu A, Capelli B, Celletti A, Cassina T, Ferrari E, Gallo M, Casso G, Landoni G: Perioperative statin therapy in cardiac surgery: A meta-analysis of randomized controlled trials. Crit Care 20, 395 (2016)

73. Wood GW, Eckert GP, Igbavboa U, Muller WE: Statins and neuroprotection: A prescription to move the field forward. Ann $\mathrm{N}$ Y Acad Sci 1199, 69-76 (2010)

74. Billings FT, Hendricks PA, Schildcrout JS, Shi Y, Petracek MR, Byrne JG, Brown NJ: High-dose perioperative atorvastatin and acute kidney injury following cardiac surgery: A randomized clinical trial. JAMA 315, 877-888 (2016)

75. Zheng Z, Jayaram R, Jiang L, Emberson J, Zhao Y, Li Q, Du J, Guarguagli S, Hill M, Chen Z, Collins R, Casadei B: Perioperative rosuvastatin in cardiac surgery. N Engl J Med 374, 1744-1753 (2016)

76. Bellomo R: Perioperative statins in cardiac surgery. JAMA 315, 873-874 (2016)

77. Maglione V, Marchi P, Di Pardo A, Lingrell S, Horkey M, Tidmarsh E, Sipione S: Impaired ganglioside metabolism in Huntington's disease and neuroprotective role of GMI. J Neurosci 30, 4072-4080 (2010)

78. Yanagisawa K: Role of gangliosides in Alzheimer's disease. Biochim Biophys Acta 8, 1943-1951 (2007)

79. Carolei A, Fieschi C, Bruno R, Toffano G: Monosialoganglioside GMl in cerebral ischemia. Cerebrovasc Brain Metab Rev 3, 134-157 (1991)

80. Mahadik SP, Hungund BL, Gokhale VS, Ortiz A, Makar TK, Karpiak SE: Monosialoganglioside (GMI) restores membrane fatty acid levels in ischemic tissue after cortical focal ischemia in rat. Neurochem Int 23, 163-172 (1993)

81. Redmond JM, Gillinov AM, Blue ME, Zehr KJ, Troncoso JC, Cameron DE, Johnston MV, Baumgartner WA: The monosialoganglioside, GMl, reduces neurologic injury associated with hypothermic circulatory arrest. Surgery 114, 324-332 (1993)

82. Tseng EE, Brock MV, Lange MS, Troncosos JC, Blue ME, Lowenstein CJ, Johnston MV, Baumgartner WA: Monosialoganglioside GMl inhibits neurotoxicity after hypothermic circulatory arrest. Surgery 124, 298-306 (1998)

83. Argentino C, Sacchetti ML, Toni D, Savoini G, D'Arcangelo E, Erminio F, Federico F, Milone FF, Gallai V, Gambi D: GMl ganglioside therapy in acute ischemic stroke. Stroke 20, 1143-1149 (1989)

84. Grieco G, D'Hollosy M, Culliford AT, Jonas S: Evaluating neuroprotective agents for clinical anti-ischemic benefit using neurological and neuropsychological changes after cardiac surgery under cardiopulmonary bypass. Stroke $27,858-874$ (1996)

85. Kharlamov A, Zivkovic I, Polo A, Armstrong DM, Costa E, Guidotti A: LIGA20, a lyso derivative of ganglioside GM1, given orally after cortical thrombosis reduces infarct size and associated cognition deficit. Proc Natl Acad Sci U S A 91, 6303-6307 (1994)

86. Farag E, Chelune G, Schubert A, Mascha EJ: Is depth of anesthesia, as assessed by the bispectral index, related to postoperative cognitive dysfunction and recovery? Anesth Analg 103, 633-640 (2006)

87. Moyce Z, Rodseth RN, Biccard BM: The efficacy of perioperative interventions to decrease postoperative delirium in non-cardiac surgery: A systematic review and meta-analysis. Anaesthesia 69, 259-269 (2014)

88. Radtke FM, Franck M, Lendner J, Kruger S, Wernecke KD, Spies $\mathrm{CD}$ : Monitoring depth of anaesthesia in a randomized trial decreases the rate of postoperative delirium but not postoperative cognitive dysfunction. Br J Anaesth 110, i98-i105 (2013)

89. Schell RM, Kern FH, Greeley WJ, Schulman SR, Frasco PE, Croughwell ND, Newman M, Reves JG: Cerebral blood flow and metabolism during cardiopulmonary bypass. Anesth Analg 76, 849-865 (1993)

90. Conolly S, Arrowsmith JE, Klein AA: Deep hypothermic cardiac arrest. Contin Educ Anaesth Crit Care Pain 10, 138-142 (2010)

91. Ziganshin BA, Elefteriades JA: Deep hypothermic circulatory arrest. Ann Cardiothoracic Surg 2, 303-315 (2013)

92. Baumgartner WA: Neuroprotection in cardiac surgery. Ann Thorac Surg 79, S2254-S2256 (2005)

93. Hogue CW, Palin CA, Arrowsmith JE: Cardiopulmonary bypass management and neurologic outcomes: An evidence-based appraisal of current practices. Anesth Analg 103, 21-37 (2006)

94. Bernard SA, Gray TW, Buist MD, Jones BM, Silvester W, Gutteridge G, Smith K: Treatment of comatose survivors of out-of-hospital cardiac arrest with induced hypothermia. N Engl J Med 346, 557-563 (2002)

95. Tarakji KG, Sabik JF, Bhudia SK, Batizy LH, Blackstone EH: Temporal onset, risk factors, and outcomes associated with stroke after coronary artery bypass grafting. JAMA 305, 381-390 (2011)

96. Dietrich W, Busto R, Valdes I, Loor Y: Effects of normothermic versus mild hyperthermic forebrain ischemia in rats. Stroke 21, 1318-1325 (1990)

97. Warner DS, McFarlane C, Todd MM, Ludwig P, McAllister AM: Sevoflurane and halothane reduce focal ischemic brain damage in the rat: Possible influence on thermoregulation. Anesthesiology 79, 985-992 (1993)

98. Grigore AM, Grocott HP, Mathew JP, Phillips-Bute B, Stanley TO, Butler A, Landolfo KP, Reves JG, Blumenthal JA, Newman MF: The rewarming rate and increased peak temperature alter neurocognitive outcome after cardiac surgery. Anesth Analg 94, 4-10 (2002)

99. Schoenburg M, Kraus B, Muehling A, Taborski U, Hofmann H, Erhardt G, Hein S, Roth M, Vogt PR, Karliczek GF, Kloevekorn WP: The dynamic air bubble trap reduces cerebral microembolism during cardiopulmonary bypass. J Thorac Cardiovasc Surg 126, $1455-1460$ (2003)

100. Whitaker DC, Newman SP, Stygall J, Hope-Wynne C, Harrison MJG, Walesby RK: The effect of leucocyte-depleting arterial line filters on cerebral microemboli and neuropsychological outcome following coronary artery bypass surgery. Eur J Cardiothorac Surg $25,267-273$ (2004)

101. Wimmer-Greinecker G: Reduction of neurological complications by intra-aortic filtration in patients undergoing combined intracardiac and CABG procedures. Eur J Cardiothorac Surg 23, 159-164 (2003) 